\title{
TRAGEDIA DE SAN HERMENEGILDO
}

\author{
Cayo González GutiérRez
}

UNED

La Tragedia de San Hermenegildo, aún inédita, es la obra más importante del teatro jesuítico, y, según la opinión de distintos críticos, una de las más importantes del siglo XVI español ${ }^{\perp}$. Varios especialistas han lamentado que siga aún inédita. Tan sólo Justo García Soriano ha dedicado suficiente espacio para la descripción de esta obra; los demás han seguido sus teorías casi literalmente 2 .

1 Ruiz Ramón, Francisco, Historia del teatro español, 2.' ed., Madrid, Alianza Editorial, 1971, págs. 109-110.

2 Garcla Soriano, J., El teatro universitario y humanistico en España, Toledo, Talleres tipográficos de don Rafael Gómez Méndez, 1945; Garcia Soriano, Justo. «El teatro de Colegio en España. Noticia y examen de algunas de sus obras». Boletín de la Real Academia Española, XIV (1927) 234-277; 3744-1I; 535-565; 620-650; XV (1928) 62-93; 145-187; 396-466; 65I-669; XVI (1929) 80-106; 223-243; XIX (1932) 485-498; 608-624; GarZÓn BlanCO, ARMANDO: «La Tragedia de San Hermenegildo, en el teatro y en el arte*. Estudios sobre La literatura y arte dedicados a Emilio Orozco Diaz, 11, Granada, Universidad, 1979, págs. 91-108; MAZUr, OLEH, Breve Historia del teatro español anterior a Lope de Vega; tramas, temas, tipos y modos, Playor (Col. Nova Scholar), 1990; OLMEDO, FéluX, Notas manuscritas sobre el teatro en los Colegios de Jesuitas, Archivo del Colegio-Noviciado de S. Estanislao de PP. Jesuitas de Salamanca [distintas carpetas y cajas]; Rovx, LuCETte Elyane, *Cent ans d'expérience théatrale dans les Colleges de la Compagnie de Jesús en Espagne. Deuxième moitié du XVI siécle. Première moitié du XVII siècle», Dramaturgie et Societé: rapports entre l'oeuvre théatrale, son interprétation et son public aur XVI et au XVII siècles. Edic. J. Jacquot, París, 1968, vol. Il, 479-523; RUGGERIO, MICHAEL, S. J., «The tragedia de San Hermenegildow, Folio 12 (1980) june, 118-128; SEgurA, FLoRENCIO, S. J., «El teatro en los Colegios de Jesuitas», Miscelánea Comillas, 43 (1985) 299-327. 
Está ya en prensa la edición crítica de esta obra, [Tragedia de San Hermenegildo del P. Hernando de Avila; Edición y notas de Cayo González Gutiérrez, Gijón, 1993 (en prensa)] de la cual ya hemos hecho una amplia descripción ${ }^{3}$.

De esta tragedia tenemos dos copias; una se conserva en un volumen con letra del siglo XVI, que contiene 162 folios $^{4}$, sin numerar. Actualmente se encuentra en la Biblioteca de la Real Academia de la Historia, con la signatura $12-12-3$, n. 386 y con la signatura actual 9/2567. Es casi seguro que vendría junto con los MS. de Pedro Pablo de Acevedo de la Librería del Colegio de San Hermenegildo de Sevilla. Al final de dicho manuscrito figura una inscripción: «Hispali, anno 1591 » $^{5}$. Otra copia se conserva en el Colegio de San Ignacio, de Alcalá de Henares, donde se encuentra el Archivo de la Provincia de Toledo de la Compañía de Jesús. Actualmente tiene la signatura M-325 (antigua 1299) ${ }^{6}$.

\section{A) Problemas sobre Autoría y Fecha}

Lo mismo García Soriano que la mayoría de críticos que le han seguido consideran como anónima la Tragedia de San Hermenegildo, salvo algunos que equivocadamente la atribuyen a Mal-Lara; tales son los testimonios de Matute ${ }^{7}$ y Pfandl ${ }^{8}$. Garzón Blanco, ya en 19749, afirmaba que la Tragedia de San Her-

3 Gonzalez Gutiérrez, Cayo, El teatro jesuístico en la Edad de Oro, MS, Oviedo, 1991. Aparecerá publicado en la totalidad en la revista: Cuadernos para investigación de la literatura hispánica, n. 20 y 21.

${ }^{4}$ En realidad la obra acaba en el fol. $120 \mathrm{v}$; después comienza de nuevo el fol. 1 con la Primer parte del Entretenimiento, hasta el fol. 42.

5 Tragedia de San Hermenegildo, Biblioteca de la Real Academia de la Historia, MS., 9/2567.

6 Ávila, HeRnando de, Tragedia divi Ermenegildi Regis facta Hispali, 1590, MS., M-325 (antiguo 1299), Archivo de Toledo de la Compañfa de Jesús, Alcalá de Henares.

7 MATUTE, Noticias relativas a la Historia de Sevilla que no constan en sus Anales, recogidas de diversos impresos y manuscritos, pág. 202, MS. de la Biblioteca Colombina. Cito por Garcla Soriano, J., op. cit., pág. 87.

8 PFANDL, L., Historia de la literatura nacional española en la E de Oro, 2." ed., Barcelona, Araluce, 1929, pág. 113.

9 Garzón Blanco, Armando, «Note on the Authorship of the Spanish Jesuit play of San Hermenegildo, 1590», Theatre Survey (1974), págs. 79 y ss. 
menegildo había sido escrita en colaboración entre el P. Hernando de Ávila, Melchor de la Cerda y Juan de Arguijo.

Según un MS. localizado por Garzón Blanco en la Universidad de Granada (Caja A-40), el P. Hernando de Ávila, escribió los actos primero, segundo, cuarto y quinto de la tragedia, y los tres actos del Entretenimiento, y fue asistido por el P. Melchor de la Cerda, S. J., eminente escritor, que fue el que se ocupó de las partes en latín de la tragedia. El tercer acto habría sido escrito, según el MS encontrado, por el sevillano don Juan de Arguijo.

El P. Astrain ${ }^{10}$ dice que el Padre Hernando de Avila compuso Tanisdorus, San Hermenegildo y Santa Catalina (es posible que por la atribución de Uriarte). Lo mismo afirma el P. Villoslada ${ }^{11}$ (supongo que por la misma razón). El P. Olmedo también afirma categóricamente la autoría de Ávila sobre la Tragedia de San Hermenegildo, la Comedia de Santa Catarina y Tanisdorus.

J. E. Uriarte y M. Lecina ${ }^{12}$, aunque no nos dan ningún dato del P. Hernando de Ávila, y dicen que no aparece en ningún Catálogo ni ninguna Historia de la Provincia, presentan como suyas las siguientes obras:
A. Tragedia Divi Ermenegildi Regis facta Hispali in Collegio So- cietatis Jesu anno 1590 die 21 januarii. Por el P. Hernando de Ávila eiusdem societatis, en 4.", 49 hs. s.n. Consta de cinco actos y está en latín y cast. (Archivum Toletanum).
B. Comedia de Sancta Catarina, dedicada a D. Francisco Reinoso; 91 hs. en 4 actos intermediada de un entretenimiento dramático dividido en partes.
C. Historia Ninives. Tragicomedia en 4 actos, con prólogo, coros y entreactos, en verso y prosa, lat. y cast.
D. Comedia alegórica con prólogo y entreactos en lat. y cast.
E. Coloquio de la Nativ. de Cristo N. Señor ${ }^{13}$.

10 Astrajn, A., Historia de la Compañia de Jesús en la Asistencia de España, Madrid, Sucesores de Rivadeneira, 1902-1925, III, pág. 379.

1 Garcla Villoslada, R., Manual de Historia de la Compañía de Jesús (1540-1940), 2." ed., Madrid, Compañía Bibljográfica Española, 1940, pág. 379.

12 URIarte, José Eugenio de y Lecina, Mariano, Biblioteca de Escritores de la Compañía de Jesús desde sus comienzos hasta 1773. Parte I: Escritores de quienes sólo se conocen manuscritos, Madrid (viuda de López del Horno, Gráfica Universal), 1925-1930, pág. 376.

${ }^{13}$ Las dos primeras obras citadas por URIARTE-LECINA se encuentran en el MS. M-325, ya citado, del Archivo de Toledo; la tercera, Tragedia Ninives, la hemos visto en el MS. M-338, también en el Archivo de Toledo. 
No son muchos los datos que tenemos del P. Ávila. Las noticias más fidedignas son las del Catálogo de la Provincia de Andalucía, de $1599^{14}$.

Es natural de Málaga; tiene 42 años de edad y 22 de Compañía. Ha estudiado siete años de derecho, tres de artes y cuatro de Teología. Hizo la profesión el día 21 de julio de 1594. Leyó un año de Gramática, un curso de Artes y ocho de Teología Moral. Reside actualmente en la casa profesa de Sevilla y se ocupa en confesar y predicar. Tiene poca salud.

Nació en Málaga en 1558 ${ }^{15}$; Ingresó en la Orden en 1579; Profesor de los Colegios de Sevilla, 1585-1591; Baeza y Córdoba, 1597; Casa Professa de Sevilla, 1600; pasó a la orden de S. Francisco de Paula en 1601. Sabemos que dedicó una comedia ${ }^{16}$ al obispo de Córdoba D. Francisco Reinoso, que estuvo en esa diócesis entre 1579 y 1603.

No sabemos cuándo murió. En los Catálogos siguientes no vuelve a aparecer. Además de las cuatro piezas mencionadas, conocemos del P. Ávila un Coloquio de los dos gloriosos Juanes (CC., MS. 389; actual, 9/2570).

Ha habido abundantes problemas con las fechas. Según García Soriano, el primer investigador que estudió con cierta profundidad esta tragedia, fue representada en la inauguración del nuevo Colegio de Sevilla, que tuvo lugar (según él) en 1580, bajo la advocación y el nombre de San Hermenegildo. Para Soriano, la fecha de 1591, que aparece en el manuscrito de la Academia de la Historia, puede ser la fecha en que volvió a representarse con motivo de la fiesta de canonización del Príncipe que después fue mártir, Hermenegildo ${ }^{17}$. Posteriormente se represento otras muchas veces.

Desde 1579 se había decidido crear un nuevo Colegio, «... obtenidas las licencias necesarias, avían comenzado a edificar, con advocación del Santo Rey de Sevilla Hermenegildo, ayudando el Cabildo de la ciudad con cinco mil ducados de limosna... y se executó la translación, a diez de setiembre de $[1580]^{18}$. 145 , nota.

14 Citado por Olmedo, F., Las fuentes de la vida es sueño, Madrid, Voluntad, 1928, pág.

15 Cfr. Garzon Blanco, Armando: «La Tragedia de San Hermenegildo, en el teatro y en el arte». Estudios sobre la literatura y arte dedicados a Emilio Orozco Diaz, II, Granada, Universidad, 1979, pág. 95.

16 Comedia Santa Catharina, M-325 (ya citado).

17 La canonización tuvo lugar, realmente, en 1585.

18 Anales de Sevilla, año de 1580; el cronista era Ortíz de Zúniga; cito por G. SORIANo, op. cit. pág. 86, nota. 
El nuevo Colegio recibió el nombre de San Hermenegildo recordando al Príncipe que murió mártir de su fe y por mandato del Rey su padre (sucedí en el año 584). Según Soriano ${ }^{19}$, con el traslado de los estudios al nuevo Colegio se hicieron grandes fiestas religiosas y literarias. En esa fecha habría tenido lugar la primera representación de la Tragedia de San Hermenegildo y también de un «entretenimiento» con claras referencias a este suceso $^{20}$.

Naturalmente, muchos investigadores siguen a Soriano y dan por buena la fecha de 1580 como la fecha de representación ${ }^{21}$. Todavía complicó más los problemas de datación de la obra de extracto que, de la Relación del Conde del Águila ${ }^{22}$, hizo don José Sánchez Arjona en su obra Noticias referentes a los anales del teatro en Sevilla desde Lope de Rueda hasta fines del siglo XVII (pp. 39 a 42). Equivocadamente, Sánchez Arjona incluye la fecha de la representación de la tragedia en el año 1570 , quizá influenciado por la opinión de Matute $^{23}$, que atribuía la obra a Mal-Lara.

Díez Borque ${ }^{24}$ recoge esta teoría y señala 1570 como fecha de la primera representación. A. Hermenegildo señala que ambas teorías son poco convincentes ${ }^{25}$. Pfandl ${ }^{26}$ atribuye la obra a Mal-Lara pero no dice nada de ella.

Para Segura ${ }^{27}$, la fecha de representación fue la de 1590 , siguiendo quizá la pauta marcada por el P. Olmedo ${ }^{28}$, quien defiende la fecha de 1590 dando como testimonio la copia encontrada en el Archivo de Toledo con el título: «Tragedia divi Ermenegildi Regis facta Hispali in collegio societatis Jesu an-

19 lbidem, pág. 87.

20 No obstante el mismo Soriano en la pág. 28, al hablar de otras representaciones, cita esta tragedia y dice que se presentó el año de 1591, con motivo de la canonización del Santo por Sixto V a instancias de Felipe II. Ya dijimos que la canonización fue realmente en 1585.

21. Rooux, Elyanne, op. cit., pág. 503; Mazur, O., op. cit., pág. 197; Flecniakoska, J. L., La formation de l'auto religieux en Spagne avant Calderón (1550-1635), Montpellier, P. Dhan, 1961, pág. 230. Águila.

${ }_{22}$ Relación manuscrita conservada en el Archivo Municipal de Sevilla, T. XV del Conde del

${ }^{23}$ MATUTE, Noticias relativas a la Historia de Sevilla que no constan en sus Anales, recogidas de diversos impresos y manuscritos, pág. 292, MS. de la Biblioteca Colombina. Cito por GARCIA SORIANO, J., op. cit., pág. 87.

24 Diez Borque, J. M. y otros, Historia del Teatro en España, Madrid, Taurus, 1983, pág. 700 .

25 Hermenegildo, A., La Tragedia en el Renacimiento español, Bancelona, Planeta, 1973, págs. 97 y ss.

26 PfandL, L., op. cit., pág. 113.

27 Segura, Florenclo, art. cit., pág. 301.

28 OlMedo, F., op. cit., pág. 144. 
no 1590 die 21 Januarii, por el P. Hernando de Ávila ejusdem societatis». Esta copia vista por el P. Olmedo en el Archivo de Toledo es citada también por Armando Garzón Blanco (quien, por otra parte, parece desconocer esta cita de Olmedo).

Armando Garzón Blanco mantiene la inexactitud de la afirmaciones de García Soriano y sus seguidores, puesto que basaban fundamentalmente, para la cronología de la Tragedia, sus investigaciones en la información de Diego Ortiz de Zúñiga que, en su crónica, da 1580 como fecha de la inauguración oficial del local, que, según Garzón, no era el nuevo Colegio diseñado por el P. Villalpando para el nuevo Colegio de San Hermenegildo, sino varias casas que se adaptaron para el uso docente, según un MS. localizado por dicho autor en la Universidad de Granada, titulado: Historias del Colegio de San Hermenegildo, y que pertenece a un voluminoso tomo de documentos jesuíticos rotulado «Papeles varios... manuscritos... del Padre Pedro de Montenegro... que los recogió en este tomo en el año 1661 (Biblioteca de la Facultad de Letras, Universidad de Granada [Caja A-40])». Nos consta la inauguración del Colegio y la primera representación de la Tragedia de San Hermenegildo, el año de 1590, en la carta anual que enví́ el director del Colegio, P. Luis de Escobar, S. J., a los superiores de la orden en Roma: Annuae litterae Provinciae Beticae Societatis Jesu anno D. mille... quin... nonagessimo primo [Caja A-40], 386.

Posteriormente Garzón Blanco encontró o vio, mejor dicho, el MS. ya citado por Olmedo, en el Archivo de la Provincia de Toledo, en Alcalá de Henares $^{29}$. Contiene esta copia un prólogo y cinco coros que no estaban en la copia de la Academia de la Historia.

Investigaciones propias llevadas a cabo en el Archivo de Toledo de la Compañía de Jesús, que actualmente se encuentra en el Colegio San Ignacio de Alcalá de Henares, corroboran la tesis mantenida por Garzón Blanco al menos en algunos aspectos. En dicho Archivo hemos encontrado un MS. que nadie hasta ahora había citado. Dicho MS. lleva la signatura actual de M-297 (antigua, M-1244), y se titula: Compendio historial de la Congregación de N. Señora de la Anunciata de Sevilla sita en su Capilla del patio de las Escuelas del Colegio de San Hermenegildo de la Compañia de Jesús de la ciudad de Sevilla, desde el año 1581 que fue el de su erección y establecimiento hasta fin del año

29 Hernando de ÁviLA, S. J., Tragedia divi Ermenegildi Regis..., Archivo privado de la Compañía de Jesús, Provincia de Toledo, Alcalá de Henares, MS. M-1299 (actual: M-325); Cfr. Garzón Blanco, A., "La tragedia de San Hermenegildo en el teatro y en el arte», Estudios literarios dedicados a Emilio Orozco Diaz, II, Granada, Universidad, 1979, págs. 95 y ss. 
pasado de 1761. En el Cap. 1 se da noticia del establecimiento de la Compañía, de la fundación del Colegio de San Hermenegildo, de la erección de la Congregación de la Anunciata... ${ }^{30}$.

Según este MS., primero llegaron a Sevilla 3 Padres, por el año $1554^{31}$, que hasta el año 1558 estuvieron hospedados al menos en dos partes,

primero en el Hospital del Amor de Dios, y después en unas Casas frente al convento de Religiosas Dominicas de Santa María de Gracia en la collación de San Miguel; en dicho año de 1558 se pasaron a otras casas principales en la collación de San Salvador, en las cuales comenzaron su primera fundación en esta ciudad con título de Colegio, en donde se abrieron clases de buenas letras, Grammatica, Rethorica y Filosophia, y después en el año de 1579, a 19 de Setiembre, se separaron algunos Padres a otras casas también principales en la collación, y frente de San Miguel, a formar Colegio de estudios con título de San Hermenegildo Mártir, Rey de Sevilla, que es donde oi permanece, dexando en aquella casa de su primera fundación los demás Padres con título de Casa Profesa: la qual estrenó la Grande Iglesia, y famoso Templo, que oi tiene, a Sábado 27 de Diciembre, día de San Juan Evangelista y tercero de Pasqua de Navidad de dicho año $1579 .$.

En el fol. 2 sigue:

Establecido el Colegio de San Hermenegildo en las referidas casas principales frente de San Miguel, formaron los Padres classes, Capilla, y todas la oficinas precisas en las Salas, y Piezas de dichas casas hasta que la ciudad, después de algunas contradicciones, y dificultades que tuvo, que vencer, comenzó en el año de 1585 a labrar el Patio de estudios con todas sus clases, y Capilla para los Padres en uno de los ángulos de él, y acab6 la obra dentro de tres años en el de $1590^{\circ}$

30 La Anunciata era una Congregación o Asociación formada por alumnos del Colegio y a la que pertenecían normalmente los mejores y más aplicados.

${ }^{31} \mathrm{Al}$ inspeccionar S. Francisco de Borja las casas adquiridas para el Colegio, le parecieron demasiado lujosas, y prefirió alquilar unas más sencillas. Cfr. ASTRAIN, A., op. cit., I, 432-433; SAA, O. E., El teatro escolar de los Jesuitas. La obra dramática de Pedro Pablo de Acevedo (15221573), MS., A dissertation of Tulane University, 1973, pág. 42. 
(Sigue hablando de la Congregación). Y aún añade en el fol. 4:

Y esta santa Capilla, que la ciudad fabricó para los Padres del Colegio con toda la obra del Patio de Escuelas, a cuio quadro pertenece, la usaron los Padres 30 años cabales desde el de 1590, en que, como ya se dixo, se perfeccionó toda la obra, hasta el de 1620, en el qual se trasladaron... a su nueva Iglesia

Este MS., que ampliamente hemos citado, señala sus fuentes:

y lo demás acerca del establecimiento de la Compañía en esta ciudad, y fundación de este Colegio de San Hermenegildo, consta de la historia del mismo Colegio, que está manuscrita en el aposento del Padre Ministro de él, y de varios apuntamientos que están en el Noviciado de S. Luis, y de la Historia de esta Provincia de Andalucía que está en el Colegio de Granada $^{32}$, de donde los sacó un curioso, y últimamente, del libro, que con el título de Historia de Sevilla escribió el Licenciado Alonso Morgado y se imprimió el año 1587.

Sobre el mismo tema hemos encontrado otro MS. del P. Roa, en el mismo Archivo de Toledo de la Compañía de Jesús, con la signatura C-184 (antiguo 1311), cuyo título escrito posteriormente es como sigue: Historia de la Provincia de Andalucía de la Compañía de Jesús escrita por el P. Martín de Roa de la misma Compañía. En el fol 170v dice:

Dieron al collegio las cassas y pasáronse a ellas en 10 de Setiembre de 80, maestros y estudiantes con su Prefecto el P. Luis Álvarez, hombre humilde, docto, inteligente en escuelas, a quien se dieron también las veces de superior... Tomaron por patrón titular del Collegio al Bienaventurado Mártir S. Hermenegildo Rey ...debajo de cuyo amparo a crecido siempre hasta llegar al punto que tiene quando esto escribimos este año de 1602

32 Probablemente la citada por Garzón Blanco como vimos más arriba o la del P. ROA que citamos más abajo. 
Dice después que en el 81 compraron otras casas del Duque de Medina Sidonia «para que en medio de las suyas pudieran mejorarse». Este es un testimonio muy cercano a los hechos que nos ocupan.

El P. Santibáñez ${ }^{33}$ dice:

Acabóse este año (1589) la suntuosa fábrica de escuelas que la ciudad nobilísima de Sevilla a sus expensas y con generosa magnificencia nos labró, teatro honrroso a la ciencia, i taller acomodado a la labor de piedras vivas, a la ciencia de sus hijos, Consta de doce clases y un hermoso patio que se espacia por cien pies de cuadro, sin los cuatro corredores que lo cercan,

Y continúa el P. Santibáñez ${ }^{34}$ :

Hallábase con esto la Compañía de Jesús empeñada con tantos favores y por hazer de sus muchas obligaciones justo reconocimiento, acordaron aquellos padres de el Colegio, que a la posesión que la ciudad avia de tomar de sus Escuelas y Teatro, acompañase un ingenioso coloquio cuio argumento fuese las glorias de Sant. Ermenegildo su patrón y titular de nuestro templo. Representaronle con tanta magestad y lucimiento nuestros estudiantes...

También hemos comprobado, en ese mismo Archivo de la Provincia de Toledo, el MS. M-325 (antiguo 1299). Dice así: Tragedia Divi Ermenegildi Regis facta Hispali Collegio Societatis Jesu Anno 1590 die 21 Januarii. Por el P. Hernando de Ávila eiusdem Societatis. A continuación trae los personajes de la tragedia y del entretenimiento. Se trata de una copia hecha en 1611; así figura en el fol. 53v. Por su importancia vamos a transcribir parte del Prólogo de ese MS. que no venía en el MS. de la Academia de la Historia:

Los ánimos agradecidos quando se ven obligados con muchas mercedes y no tienen posibilidad para servillas o a lo menos procuran ofrecer algún presente que aunque sea de poco valor sirva de testimonio, sirva de reconocimiento... lo que los estudiantes de estas escuelas debemos a V.

33 Santibañez, P., Historia de la Provincia de Andalucía, pte. 2. , 1. 3, c. 46, n. ${ }^{\circ} 6$.

34 Ibidem, n. 7. 
S. sin que yo lo diga lo dizen a boces las paredes deste tan insigne edificio, deseando pues acudir a nuestra obligación y presentar algo a V. S. no hallamos otra cosa más a propósito que presentarnos a nosotros mismos y representar lo que nos pareció sería de más gusto. V.S. a querido casar en estas escuelas el fabor del santo Rey Ermenegildo con la profesion de las buenas letras y para este casamiento a hecho de nuebo esta casa real, acordamos pues de representar la vida del que V.S. nos da por padre que es el santo hermenegildo para que guste V S. cómo començamos poniendonos delante de los ojos el exemplo que avemos de imitar...

Esta obra está estructurada, como la mayoría de las obras jesuíticas del siglo XVI, en CINCO ACTOS. La tragedia está perfectamente construída en su exposición, nudo y desenlace. Por otra parte, guarda una considerable fidelidad histórica a los acontecimientos narrados y a los personajes, dentro de las lógicas dificultades por la escasez de estos datos históricos. Debemos resaltar el hecho de que no se respeten las unidades de lugar y tiempo...

Es una obra de las que se podrían llamar de «circunstancias». Los autores de la Compañía de Jesús no escribían habitualmente por inspiración puntual. Normalmente lo hacían por imposición. Los Profesores de Retórica eran los encargados de escribir las obras que se habían de representar en las fiestas anuales y en las circunstanciales. Como hemos visto en la cita del Prólogo, en esta ocasión, el P. Ávila escribe, como Profesor de Retórica del Colegio de San Hermenegildo de Sevilla, una obra cuyo título y argumento viene condicionado por el evento de la inauguración del Colegio dedicado al Santo Patrono del Colegio.

\section{B) ACtores y Personajes}

Los nombres de los actores de los diferentes papeles de la Tragedia han llegado a nosotros en una Relación de dicha fiesta, que se conserva en el Archivo Municipal de Sevilla (T. LXV del Conde de Águila; relación manuscrita e incompleta de dicha fiesta ${ }^{35}$ ).

Participaron en la representación de la obra ochenta actores; treinta y dos en la tragedia propiamente dicha y otros siete en el Entretenimiento. Estos

35 Cito por García Soriano, J., op. cit., pág. 87. 
treinta y nueve actores tenían en la obra partes habladas. El resto aparecían acompañando a los otros personajes principales.

Entre los personajes que aparecen en la Tragedia, algùnos son alegóricos, tales como la ciudad de Sevilla, Cazalla, Carmona y Axarafe. Otro personaje alegórico es el Temor presente siempre en Hermenegildo. Los otros quizá adquieren una importancia especial al provocar los monólogos o diálogos interiores de Hermenegildo; se llaman: El Deseo, La Fe, El Zelo y La Constancia. Es curiosa la aparición, a veces, de estas figuras alegóricas; así, el Zelo, con una espada, toca los hombros y la cabeza de Hermenegildo; la Constancia lo protege con la rodela; la Fe le proporciona la celada y el Deseo le calza las espuelas... El empleo de personajes alegóricos era muy frecuente en las obras dramáticas de los Colegios de los Jesuitas, en el siglo XVI.

PERSONAJES ${ }^{36}: 1 .^{\circ}$ el Rey Ermenegildo, $2 .^{\circ}$ San Leandro Arçobispo de Sevilla, 3 Un cardenal Legado del Papa, 4 Gosindo (Grande del Consejo de S. Ermenegildo), 5 Leodegario (Grande del mismo Consejo), 6. Intérprete, 7 Hortensio (envajador romano), $8 \mathrm{El} \mathrm{Temor,} 9 \mathrm{El} \mathrm{Deseo,}$ $10 \mathrm{El} \mathrm{Zelo,} 11 \mathrm{La} \mathrm{Fee,} 12 \mathrm{La}$ Constancia, 13 Un paje de S. Ermen., 14 Ingunda (reyna), 15 Sevilla (dama de Ingunda), 16 Cazalla (otra dama), 17 Carmona (otra dama), 18 Axarafe (otra dama), 19 paje de estoque de S. Ermen., 20 El Rey Leovigildo, 21 Recaredo (Príncipe), Alcaide del Castillo, Primero, $2 .^{\circ}, 3^{\circ}$ soldados del muro, Flaminio (capitán italiano), Curcio (otro capitán), Sisberto (verdugo), Angel, Celio (caballero), Un niño infante (hijo de S. Ermenegildo), Pascasio (Obispo ereje) ${ }^{37}$.

\section{C) Temática y ARgumento}

Las obras de teatro de los Colegios de Jesuitas fueron dramas ciertamente complejos. Rara es la obra en que no aparecen mezclados en mayor o menor

${ }^{36}$ Según la copia del MS. de Alcalá. En el MS. de la Real Academia de la Historia no trae los personajes; en la relación manuscrita conservada en el Archivo Municipal de Sevilla, T. LXV del Conde del Águila (cfr. G. SoRıANo, op. cit. pág. 87) figuran así: El Crucífero, el Cardenal Nuncio, San Leandro, Ermenegildo, Gosindo, Leodegario, Page, Hortensio, Embaxador, Intérprete, Temor, Deseo, Zelo, Fe, Constancia, Ingunda, Cuatro Damas (Hispalis, Carmona, Caçalla, Axarafe), Príncipe Recaredo,Arzobispo Paschasio, Un Secretario, Principito, Flaminio, Curtio, Leovigildo, Doce alabarderos, Tres soldados, Celio, Centinelas, Lisardo, Sisberto, Un Angel. Esta Relación incluso trae los nombres de los Actores que omitimos (pueden verse en G. SORIANO, pág. 87).

37 A continuación vienen los personajes del Entretenimiento. 
proporción elementos biblicos, teológicos, morales, clásicos, alegóricos, populares.

Uno de los temas presentes es la discusión teológica entre los obispos católico y arriano en tomo a la verdadera. Fe de la Iglesia frente a la Herejía de Arrio $^{38}$. Por otra parte, el conflicto dramático se plantea a la vez en el orden político y en el orden religioso. Leovigildo quería unir todos los Reinos peninsulares en un Cetro y un Credo (el arriano). La conversión de Hermenegildo echa por tierra todos sus planes ${ }^{39}$

\section{Argumento}

En parte nos viene dado en el Coro Primero que tenemos en la copia del Archivo de Toledo (y que falta en la de la Academia de la Historia);

Choro Primero

Alerta, ciudad illustre,

Atensión y grato oydo,

Verás el feliz progreso

De tu Rey Ermenegildo,

$O y$ el cielo a sus intentos

Se le muestra tan propisio,

Que armándole caballero

Le escoge por su caudillo;

El Zelo le ziñe espada

De temple y azeros finos,

Para que siempre los tenga

En defender su partido.

La Constancia le guamece

Del escudo y contra el tyro
Que piensa hazerle el padre

$\mathrm{Y}$ a su golpe reduzillo;

La Fe le da tal Zelada

Que el hierro del enemigo

Antes rompa su cabeça

Que descubra en ella visio;

Cálçale espuelas doradas

El Deseo ardiente y vivo, $Y$ poniendo al Temor freno Jamás pierde los estribos;

Sigue con aquestas armas,

Confiado su destino,

Que a quien el cielo asigura

Nunca es dudoso el partido.

38 Arrio fue un heresiarca griego, que negó la divinidad de Jesús; decía que sólo se le podía considerar Dios figuradamente. El Emperador Constantino convocó el Concilio de Nicea (año 325) donde se condenó a Arrio y su doctrina y se afirmó la divinidad de Jesús.

39 Vid. Olmedo, F., Notas Manuscritas, Caja 4T, fol. 16. 
ACTO I. En este acto se preparan todos los elementos que van a estar presentes en la acción ${ }^{40}$; El Nuncio propone a Hermenegildo, de parte del Papa, una alianza con Roma en contra de su padre Leovigildo por quien es perseguido aquel por convertirse al cristianismo. Hermenegildo acepta la alianza con Roma impulsado por una fuerza superior. El autor cambia aquí la fatalidad de los clásicos por la Providencia de Dios, aunque queda patente la libertad de decisión por parte del futuro mártir.

ACTO 1.-ESCENA 1: El Crucífero, el C. Nuncio, S. Leandro, con muchos pajecillos y abrazáronse los dos muy cortésmente ${ }^{41}$ (Todo en latín); ESCENA 2; lat., cast.

Lean. (traduce a Hermenegildo lo que el Nuncio dijo en latín)

Dize que el gran Pontífice Gregorio, f1. 8 , col. 2

Pastor sumo en la humana hierarchía, Desde el Sacro Palacio y Consistorio, Salud, y bendición, o Rey, te embia; Que, quando dentro en Roma fue notorio Que abjuravas la pérfida eregía, Sintió la Iglesia sancta el regosijo Qual la madre, a quien nace el primer hijo,

Su Santidad se alegra de aver visto Fl. 8 v, col. 1 Brotar en ese pecho aquel sarmiento, Que, unido con la vid, que es Jesu Christo, Vida recibe, $y$ a la fe da aumento.

Pide que, como Príncipe bien quisto, Prosigas con tan santo y justo intento; $Y$, porque tenga el fin que se desea, El tesoro eclesiástico franquea.

40 Vid. Roux, E., op. cit., pág. 504.

41 En la copia de Alcalá se concretan mucho más las «acotaciones»; dice en esta primera escena: «salió primero la Cruz de Plata del Cardenal la cual traía un crusiferario en traje de clérigo, cubierta la cabeça con su bonete; tras ella salió luego el Cardenal Legado al lado derecho de S. Leandro Archiepiscopo de Sevilla, que salió con él; detrás de ambos venían muchos pagesillos en traje de estudiantes con sus manteos y bonetes y abrasándose los dos muy cortésmente començó a hablar el Cardenal Legado y dixon. 
Y si acaso el furor del Padre injusto

Viniere a rompimiento, y a las manos,

Te ofrece, y te asegura (como es justo),

El fabor de los Príncipes Christianos;

Y que, en particular, será con gusto

De el mismo Emperador de los romanos,

Que no será de Príncipe católico

No ayudar contra orgullo tan diabólico.

Ermene.

Porque un negocio de tan grabe peso (tachado "pecho")

No me da, ni concede más licensia,

Acá sus sacros pies adoro y beso,

Como si allá estubiese en su presencia,

$\mathrm{Y}$, de mi antiguo error cobrado el seso,

Me postro, con humilde reverencia,

A los pies de el que tengo por cabeça,

Cuya virtud me rige y me endereça

Pido a su Santidad que desde oy quiera

Amparar en su aprisco, y su rebaño

Esta oveja perdida, que, zerrera,

$A$ andado en los balidos de su engaño;

Que, en fe de que esta fe es la verdadera,

No rehúso oponerme a qualquier daño,

Confiado en sus santas oraciones

$\mathrm{Y}$ en las de los fieles coraçones.

$Y$ vos, o Nuncio, en tanto que me espacio

Con Leandro, con quien mi pena amanso,

Podréis tomar descanso en el palasio

Donde yo, siendo Rey, nunca descanso,

Porque avré de tratar con vos, despasio,

(después que ayáis tomado algún descanso)

Negocios tan secretos, y tan grabes,

Que piden sello, serradura y llabes.

Sigue Leandro, en latín.

ESCENA 2-Sale Hermenegildo con 12 alabarderos de guarda los cuales se fueron en orden apartando de los lados hasta quedar en ala arimados al muro de Sevila; llegó el Cardenal Legado haziéndole una humilde inclinación; recibióle el Rey con la misma cortesía; échanse los brazos encima 
y haciendo la señal al Cardenal y al Arzobispo, Leandro que se cubriesen, dixo el Cardenal.

Ermene:

Quando la nave acá y alla vaguea,

Fl. 9, col. 1

Como liviana oja o móvil cuna,

Y quando el turbio mar sin viento ondea,

Pronóstico muy cierto es de fortuna;

Quanto menos la suerte se prevea,

Tanto temo a de ser más importuna,

Do el peligro se siente, sin ver dónde

Sopla el viento del daño que se esconce,

Veo, a mi Padre con dañado afecto,

Con el Rey Miro y otros hazer liga,

Armarse, y prepararse de secreto,

Valerse del fabor de gente amiga,

Sospecho causas, temo el mal efecto,

Mas no entiendo ni alcanço a qué me obliga.

No sé si es mi reçelo el que me engaña,

O si más grave mal me ofende y daña.

Lean:

Rei alto, el coraçón no desfalleze,

(sic) Fl. 9, col. 1

No desmaye la fe, ni la esperança;

Por más que el viento esfuerçe y el mar cresca,

Y por más que se altere la bonança.

No temas que peresca, anque padesca,

La nave que en Dios tiene confiança;

No duerme Christo, ni nos deja a solas

En el fragoso mar y turbias olas.

Aquel orgullo con que ya rebuelve,

Tu injusto, y atroz Padre, mar y tierra,

Bien clara muestra de que se resuelve

De romper contra ti en funesta guerra;

$Y$ aunque sus fines con secreto embuelve,

Más mi razón -entiendo- que no yerra.

Y por más que se oculte, en los efectos,

Se muestran y trasluzen los secretos. 
Vase S. Leandro. Hermenegildo se ratifica en sus creencias.

Erme.

Jamás tan alegre al suelo

Fl. 9 v. col. 1

Se mostró la blanca aurora,

Quando con su faz decora,

Abre las puertas del cielo,

$\mathrm{Y}$ a las nubes borda y dora.

¿Estoy soñando, o dispierto?

No duermo, que bien advierto

Que el claro sol a salido,

Pues de su luz e sentido.

Dentro de mi indicio tan cierto.

Las nubes de mis antojos

El sol divino a desecho,

Pues con notorio provecho

Su rayo toca en mis ojos

Y su calor en mi pecho.

Acto I, escena $3^{*}$

Leodeg.

Goza, Rey, sin pena alguna,

Fl. 9, col. 2

De la potencia, y alteza

Debida a tu gran nobleza,

No por suerte de fortuna

Sino por naturaleza.

Que la gloria y resplandor,

Deste tu nombre y valor,

Tanto se estiende y derrama

Que no te llama la fama

A gloria, o nombre mayor.

En la escena $3^{*}$ de este primer Acto se ensalza y alaba la tierra de Sevilla de la que Hermenegildo es Rey:

Gosindo

Mira esa fértil Carmona,

Fl. 10, col. 1

Que, de su espasiosa vega, 
Te ofrece copiosa entrega,

Tejiéndote la corona

De las espigas que ciega.

El Axarafe, en sus haldas,

Como gruesas esmeraldas,

Olibas te da en tributo,

$Y$ del liquor de su fruto

Unges tu frente y espaldas.

Caçalla, desde su sierra, Arrima sus tiernas vides

A las comunas de Alcides (corregido, antes, Midas).

$Y$ del vino que ella encierra

A todo el mundo divides.

$Y$, finalmente, si a quien

El alto Dios quiso bien,

De comer le dio en Sevilla,

¿Qué hará si le dio silla

Y trono real también?.

Intervienen en este primer Acto entre otros los siguientes personajes: El Cardenal Nuncio, San Leandro, Hermenegildo, Gosindo, Hortensio, Leodegario, Deseo, Temor, Zelo, Fe, Constancia...

\section{ACTO II}

Recaredo, hermano de Hermenegildo, viene a convencerle de que se someta a su padre. San Leandro y Paschasio debaten como estandartes de la Fe católica de Hermenegildo y la arriana de Leovigildo. El embajador romano promete ayudar a Hermenegildo en la guerra con su padre.

\section{ESCENA 1.}

Ingunda:

¡Quán infiel, quán injusto

Fl. 18, col. 1

Es o fortuna tu peso?

Do pones en contrapeso

Mil pezares para un gusto.

No sé dónde tiene el seso

El que tanto se abalança, 
Que fíe de tu balança

Negocios de grande peso.

¡O quantas vezes le pesa

Al que de un Reyno se encarga,

Pues, quando toma su carga,

Echa de ver quánto pesa!

Que el reyno, y el señorío,

De suyo, es carga pesada,

Quanto más siendo pesada

Por ageno desvarío.

¡Quién vio ayer a Ermenegildo

Burlando de la Fortuna

Sin tener mudança alguna

en su Padre Leovigildo!

¿Quién viera ayer su balança

Lebantada hasta el cielo,

Sin que temor ni reçelo

Abajaran su esperanza?

$Y$ agora, sin merecello,

Le ve puesto en tal estado

Que el peso de su cuydado

Le agobia, y oprime el cuello.

¿Cómo es posible que quadre

Un peso tan infiel,

Do por ser el hijo el fiel

Haze tan mal peso el Padre?

Mas quando Dios, al trocado,

En su balança le pese

Yo asiguro, que a él le pese

De aver sido tan pesado.

Sevilla:

Ingunda, señora nuestra, No enturbiéis el rostro agora,

Que, en tenerte por señora,

Sevilla alegre se muestra.

Humildes gracias te damos

Por la gloria que tenemos,

De que a ti sóla debemos

La Fe que por ti gozamos. 
Quán franca se mostró Francia

En darnos Princesa tal,

$Y$, siendo suyo el caudal,

Toda es nuestra la ganancia.

Y no es pequeña hazaña,

Pues, que tu fama celebra.

Que suelde Francia la quiebra

Que el godo hizo en España.

fol. 25

En la escena $4^{a}$ del $2^{\circ}$ acto interviene Recaredo, hermano de Hermenegildo.

Recaredo:

Estoy del caso atónito, y confuso

Fl. 23, col. 2

Enfrena la passión; y deja agora

Que la razón despierte su buen uso,

Advierte Ermenegildo que desdora

La sangre clara ylustre de los godos

Esa ley, que encanta, y enamora.

No degeneres por tan bajos modos

De la antigua creencia que tubieron

Y profesaron tus Mayores todos.

Gosindo (Escena 4)

Despliega, pues, o Rey, las anchas velas

Engólfate en el mar a tu aventura,

Que presto vendrá el mal que no recelas;

Quanto mayor bonança te asigura,

En el inestable golfo de tus males,

Es presagio mayor de desventuras.

Ya las torres de viento dan señales

Muy ciertas de su mísera ruyna,

Con que amenazan casos más fatales.

Ya nuestra perdición está vezina

Porque el Señor, que rige el firmamento,

Sin duda, a nuestro mal se determina.

$\mathrm{Y}$ quando caiga en tierra el fundamento

En que estriban las vanas esperanças

Será a el mundo materia de escarmiento. 
ESCENA 5: Intérprete (traduce las palabras de Hortensio, embajador de los romanos)

Intérprete:

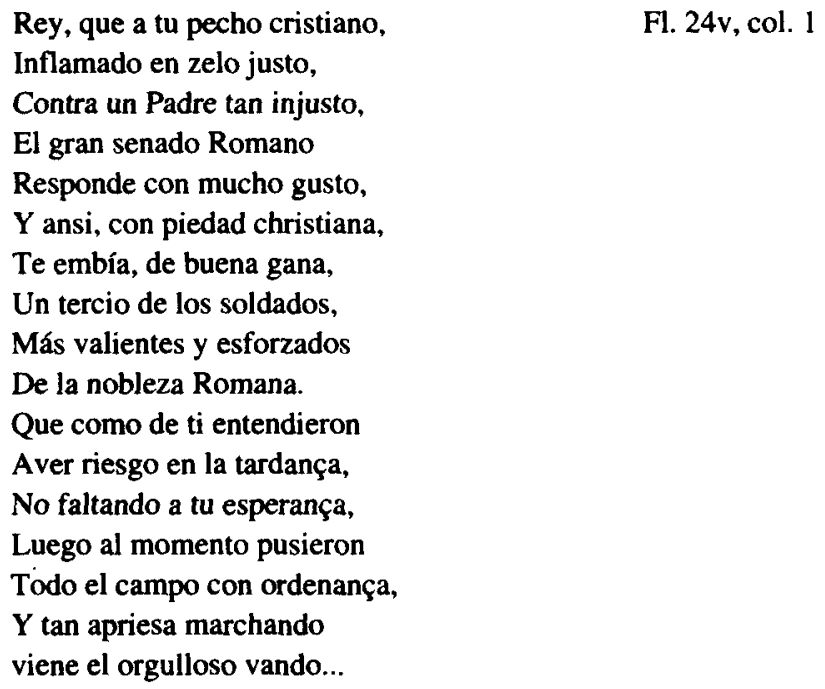

\section{ACTO III}

Los romanos traicionan el pacto y se pasan, ante las perspectivas del triunfo, al ejército de Leovigildo. Recaredo informa a su padre del fracaso de las gestiones. Este se enfurece y promete matar al hijo y arrasar Sevilla. No deja, sin embargo, de dudar con patéticas frases:

Leov:

En Sevilla se haze fuerte, Fl. 32 v., col. 1

Pensando que está seguro,

A la sombre de su muro,

De mi rigor y su muerte.

(Buélvese a la ciudad)

Perdonad, ciudad famosa, Que, en tan preciosa ocasión,

Procura tu destrución

Quien pensar en ella no osa. 
¿Será que pueda sufrir

Ver por los ayres la llama

$Y$ que do llega tu fama,

Los gritos se ayan de oír?

¿Y que los dorados techos,

Que toca su cumbre el cielo,

E de ver yo por el suelo,

En vil ceniza deshechos?

¿Y que e de ver yo tus llanos

En altas montañas bueltos,

De cuerpos en sangre embueltos

De tus nobles ciudadanos?

¿Que por fuerça an de herir

Mis lastimados oídos

Las vozes de los gemidos

De los que an de morir?*

¿Podré con alegre frente

Mirar en tu destrucción,

Dos vandos y una nación,

$\mathrm{Y}$ dos leyes y una gente?

Tú, Betis, que la enriquezes,

En señal de triste luto,

Trueca el color del tributo

Que al mar de España le ofreces,

Pues de sangrientos matices

Verás teñida tu arena,

Que con abundante vena,

La riegan tantas cervices.

A nueba pasión se inclina,

Que, en el daño que se espera,

Pida una llaga tan fiera,

Tan costosa medicina.

$Y$ que, si aquesta se toma,

Aya de saber el mundo

Que soy un Nerón segundo

Con otra segunda Roma.

¡Dulce hijo Hermenegildo!

¿Hijo? Mal dixe: ¡Enemigo

Criado para castigo

De tu padre Leovigildo!

* Los últimos 4 vv. faltan en la versión de la Academia de la Historia. 
Prosigue en atormentarme

En tu obstinada porfía,

Que a tiempo estoy que sería

Bien fácil el acabarme,

Tú, causa de mis enojos,

Que en mi daño perseveras,

Tú te ablandaras si vieras

Las lágrimas de mis ojos.

Los romanos exigen como rehenes a la Reina y al Principito. Llega Leovigildo y ataca Sevilla.

En la copia de Alcalá, al fin del $3^{\circ}$ Acto hay un CHORO que no hay en la copia de la Ac. de la Historia.

$4^{\circ}$ Choro

Lloremos nuestra triste y dura suerte, Fl. 41 v, col. 2

Rompan nuestros gemidos y lamentos

El cielo cristalino pues convierte

En tristeza fatal nuestro contento,

Ingunda n.", que con pecho fuerte

Vas dispuesta al rigor del mar y viento,

pues nos dejas aca, dulce señora,

¡Ay dios, y que haremos sin pastora!

\section{ACTO IV}

Los italianos tratan de justificar su abandono del campo de Hermenegildo. Las tropas de este son vencidas. Recaredo aconseja a su hermano que se arroje a los pies de su padre. Así lo hace. Leovigildo le dice que le restituirá el Reino si abjura de su error. Hermenegildo se niega. El padre manda ponerlo en la cárcel ${ }^{42}$. En la Escena $6^{2}$ de este ACTO IV, Ermenegildo, armado con una espada desnuda, se lamenta en unas buenas quintillas:

Ermeneg:

O turbios cielos ayrados

¿Por qué os mostráis enemigos?

42 Cfr. Roux, E., art. cit., pág. 505. Nota: es el Acto en que más se emplea el italiano por los capitanes romanos. 
¡O! ¿Cómo irán sin castigos

Traidores disimulados

Con falso beso de amigos?

Diéronme muestras de amor, Acogilos sin temor, Mas quán presto descubrieron Que era la paz que me dieron Abraço de salteador.

¿Dónde está la lealtad? ¿Dónde la fe que se debe? ¿Cómo? ¿Un Romano se atreve A romper con la amistad

Con tanta nota de aleve?

Ay de mí, que a mi despecho

E visto el aleve pecho,

La traición tan cierta y clara,

La disimulada cara,

La intención buelta en provecho...

Véome en esta fatiga

Sin soldado que me guarde,

Ya de vencido cobarde,

Do no ay mal que no me siga

$\mathrm{Ni}$ bien que no llegue tarde.

Mis conocidos me estrañan Mis enemigos me dañan, Mis amigos no me ayudan, De fe y lealtad se desnudan Los consejos que me engañan.

\section{ACTO V}

Recaredo y otros intentan, en la prisión, convencer a Hermenegildo. Traen una carta en que se anuncia la muerte de la esposa de Hermenegildo. Leovigildo, ante las peticiones de clemencia, duda.

Leovig.:

Estoy de mil congojas rodeado, Fl. 51 , col. 1 No halla pie ni vado el pensamiento, 
Que es con contrario viento combatido.

No sé quién me a metido en tal tormenta.

De todo me atormenta, ;Oh duros hados,

Contra mí conjurados! ¿Qué haré?

¡Cómo! ¿que segaré con golpe fiero

Al que más que a mí quiero, al hijo amado,

Al cordero criado en mi regazo,

Al que con dulçe abraço a mi llegaba,

$Y$ con esto engañaba los cuydados,

En ceptro vinculados? Mas, ¡qué digo!

Muera el hijo enemigo!; ¡ay, traidor cierto!

¿Que así a tu padre as muerto!, mal criado,

Lobo disimulado con pelleja

De la querida oveja, a pan criada!

Detente desbocada lengua loca;

Ten siquiera una poca de templança.

¿Que no abrá tal mudança en fe tamaña?

¡Ay, triste, que me engaña el amor ciego!

¡Muera, que es justo, luego; mas no muera!

Mi muerte sea primera, venga ya

La muerte! ¿Dónde está que no me acaba?

¿Dónde tal guerra traba el pensamiento?

Al final hay una escena de auténtica fuerza dramática y trágica, con la representación de la muerte del Príncipe:

quédase besando el Crucifixo

Fl. 53 v, col. 2

Sisberto:

Príncipe, si alguna ley

De alevosía me acusa,

Sé que del hecho me escusa

El mandamiento del Rey.

\section{Emerneg.:}

Perdonad al braço aleve,

Que a daros muerte se esfuerça,

Pues veis que es agena fuerça

La que le rige y le muebe. 
Erme.:

¡Hágase ya el sacrificio

Executad la sentencia!

Sisberto:

Con tal perdón y licencia,

Haré Príncipe mi ofisio.

Dale el golpe con la hacha en la cabeça

Ermeneg.:

Entre estos golpes tiranos

Que por ti, mi Dios, padesco,

Mi alma rindo y ofresco

En esas divinas manos.

Diziendo esto el Santo Ermenegildo cae en los braços de la Fez y la Constancia muerto y con esto se dio fin a la Tragedia, ad maiorem gloriam Dei.

D) ESCENOGRAFIA

La función fue, ciertamente, fastuosa. A ella asistieron, entre otras muchas Autoridades, el Arzobispo, el Cabildo, la Audiencia, la Inquisición, el Tribunal de Contratación, la Nobleza... En la Relación se describe incluso el escenario ${ }^{43}$ :

El estrado era de un estadio de alto y 39 pies en cuadro; en el frontispicio había una gran puerta de muy galana arquitectura, que representaba a la ciudad de Sevilla, en cuyo friso estaba un tarjetón con aquestas letras: S.P.Q.H. A los dos lados de esta puerta, de una parte y otra, corría un hermoso lienzo de un muro con sus almenas, fuera del cual, como espacio de tres pies, salían dos torres algo más altas, de las cuales la que estaba a mano izquierda sirvió de cárcel a San Hermenegildo y la que estaba a mano derecha sirvió de Castillo a los «entretenimientos». A los lados de estas

${ }^{43}$ Citado por G. SORIANO, op. cit., p. 87. 
dos torres quedaba suficiente campo, por donde salían todas aquellas personas que representaban estar fuera de Sevilla, como el Rey Leovigildo y otros; porque por la puerta de en medio solamente entraban y salían los que representaban estar dentro de Sevilla, como «San Hermenegildo», etc...

La Escenografía ${ }^{44}$ estaba compuesta por tres unidades: una torre (sirvio de cárcel), una puerta de acceso a la ciudad, un palacio (para el Entretenimiento). Entre estas unidades, telones pintados indicaban las murallas de la ciudad. Según el MS. de Alcalá, una cortina ocultaba a los actores hasta que entraban en escena. Por la puerta de la ciudad solamente entraban y salían los personajes de rango. Por las acotaciones, debió haber distintos niveles elevados del tablado.

\section{E) VALORACIÓN}

La Tragedia de San Hermenegildo tuvo tal éxito en su primera representación, que según el $P$. Santibáñez ${ }^{45}$ tuvo que ser repetida al día siguiente para poder satisfacer el clamor y peticiones de gentes importantes que el primer día no tuvieron cabida en el muy capaz teatro, patio, corredores altos y bajos y azoteas. Dice que admiró mucho la trama del asunto, la elegancia de los versos, el aire y la gracia de los que representaban, la música, y la riqueza de que se hizo gala. Pasaron, según este testimonio, de tres millones el valor de oros, joyas, cadenas, telas, pedrería.

A juicio de todos pasó de tres millones la estimación que el valor de oros, joyas, cadenas, telas y pedrería con que se mostraron ornados, bizarros y curiosos cien personajes, que salieron al tablado y entraban a componer esta pompa y representación. Afirman por muy cierto que San Hemenegildo y las dos Virtudes, Fe y Constancia, portaban sobre sí, alrededor de cien mil ducados de joyas ${ }^{46}$.

\footnotetext{
44 Vid. Garzón Blanco, A., «La Tragedia de S. Hermenegildo...», págs. 98 y ss.

45 Santibá̃ez, op. cit., parte $2 .^{*}$, I. 3., c. 46, n. 7 ; cito por Segura, F., «El Teatro en los Colegios...», pág. 301.

46 Vid. Garzón Blanco, A., «La Tragedia de S. Hermenegildo...», p. 96 y ss.
} 
La Tragedia de San Hermenegildo fue una de las obras con mayor aceptación en los distintos Colegios. Los distintos críticos que la han conocido (casi siempre a través de la descripción de Soriano) la ensalzan aunque no con total unanimidad.

Esta obra confirma la evolución que, lo mismo que en el resto de nuestras letras, se dio en el círculo concreto del teatro de los jesuitas. Más de treinta años de distancia entre las primeras obras del P. Acevedo y esta magistral obra, explican las acusadas diferencias existentes.

Es una auténtica pieza trágica, pues el interés no desfallece entre las luchas internas y externas, del padre y del hijo. Es un drama místico porque muestra cómo se llega a la santidad, a la vez que teológico por el enfrentamiento entre los obispos católico y arriano.

El éxito de la Tragedia fue extraordinario. El asunto fue adoptado enseguida en los colegios extranjeros. En cambio, fue poco utilizada por nuestros clásicos. En la Flèche, Francia, se representó en la segunda década del s. XVII una tragedia titulada «Hermenegildus, prince catholique revolté contre le roi son père, et mourant pour sa foi». Con el mismo título se puso en escena una tragedia en el Colegio Louis-le-Grand, de París, en agosto de 1664. Se volvió a representar el 4 de feb. de 1678. El P. Charles Porèe escribe más tarde otra tragedia, titulada «Hermenegildus Martyr», que se representó muchas veces en varios Colegios de Francia, y en el de París, especialmente, los años $1718,1724,1734$ y 1740 . Fue impresa con otras obras dramáticas del P. Porèe.

En Italia, también el jesuita Cardenal Sfortia Pallavicini publicó: «Hermenegildus Tragoedia in Seminario Romano recitata» (Romae, 1644) ${ }^{47}$.

\section{F) OTROS ELEMENTOS}

Casi toda la obra está escrita en vv. castellanos: octavas, tercetos, quintillas, redondillas... En latín hablan el Nuncio, el Embajador, y, a veces, el Intérprete y S. Leandro. Los capitanes italianos, en versos latinos y toscanos. En prosa latina, sólo la disputa teológica entre S. Leandro y Pascasio. Extraña en esta obra la ausencia del Coro tan frecuente y logrado en la mayoría de las obras de Colegios de Jesuitas. Como ya dije anterormente, estos casos sí existe

${ }^{47}$ Hermenegildo, AlFredo, op. cit., págs. 97 y ss. 
en la versión de Alcalá. Sí hubo, no obstante, música y efectos especiales, sobre todo referentes a sonidos, ruidos de armas, desfiles militares... En el Entretenimiento hubo distintas danzas y preparaciones coreograficas. Hay atisbos de empleo de humor en alguna escena entre soldados ${ }^{48}$.

En cuanto a la métrica la $T$. de San Hermenegildo presenta una muy interesante polimetría. Es frecuente la Octava Real, también las quintillas, las redondillas, tercetos encadenados, silva...

\section{Entretenimiento}

Entre los primeros actos de la Tragedia se intercalaron las tres partes de un Intermedio o Entretenimiento, con el cual se creb un nuevo género combinando lo cómico con la alegoría. Según García Soriano ${ }^{49}$, podría titularse: [HÉRCULES VENCEDOR DE LA IGNORANCIA]. Está en el manuscrito a continuación de la tragedia (comienza de nuevo la numeración de folios a partir del número uno).

PERSONAJES: Sciencia, Hércules, Amor de Sciencia, Amor de Honor, Honor, Ignorancia, Amor sensual, Amor interesal, Un bárbaro principal, Otros ocho bárbaros que salieron contra Hércules, Seis niños que salieron armados a danzar.

La acción se desarrolla en el mismo escenario de la Tragedia. En la misma torre que sirve de prisión a Hermenegildo hay un lugar en que está la Ciencia, prisionera de la Ignorancia. Aquella se queja de su prisión. El Amor de Sciencia va buscando el lugar donde está la Sciencia; dice que ha recorrido todo el mundo hasta Sevilla. Habla en buenas octavas reales. Salen dos gitanillos, que son el Amor Sensual y el Interesal. Hay unas escenas originales intentando decirse mutuamente la buenaventura (señalemos como nota curiosa y localista que los gitanillos «cecean» $)^{50}$.

En la segunda parte sale Hércules, que hace un elogio del reino sevillano que él fundó. Está acompañado del Amor de Sciencia y del Amor de Honor

48 El primer acto tiene 6 escenas; el segundo, 5 ; el tercero se desarrolla en 6 escenas; el cuarto tiene 8 y el quinto, 6 escenas.

49 op, cit., pág. 106. Este autor nos ofrece un amplio resumen de este Entretenimiento (págs. 106-112). Nota: en la copia del MS. de Alcalá, este Entretenimiento figura copiado en cada entreacto de la obra principal.

50 Cfr. Roux, E., art. cit., pág. 506. 
(también aquí hay una curiosidad escénica: se tiznan la cara con carbón molido que llevaban en unos canutos).

En la tercera parte Hércules vence a los Gitanillos que vigilaban la Ciencia, y que estaban armados con espadas y broqueles, y libera a esta. Sale después un león al que vence Hércules. Tiene especiales manifestaciones escénicas $^{51}$ la última escena del Entretenimiento, que se nos describe así en el Ms. de Alcalá:

Y luego cayo en tierra el muro del castillo de la ciencia en cuyo gueco se cubrían 6 grutas donde algunos niños en trage de ninfas cantaron con un mote la gala de Hércules y aquí dexó la ciencia las ropas negras y quedó con otras muy vistosas que debajo traía, tomando en las manos una rica corona y un caduceo de flores y bajó de lo alto de la torre al tablado diziendo las siguientes octabas, y entre octaba y octaba los niños cantavan los siguientes motetes; al bajar venía poco a poco hasta que llegando al suelo coronó a Hércules con una guirnalda de flores y le dio el [sic] cornucopia que traia.

Y antes dice:

Aquí salieron por las seis portañuelas, que en el tablado estaban hechas, seis niños armados, con sus broqueles y espadas pequeñas, que haziendo unas concertadas escaramuças al son de un discante, ellos mismos se mataron y volvieron a caer por las mismas portañuelas.

Tanto la tragedia como el Entretenimiento son verdaderas obras maestras, no sólo del teatro escolar, sino también de nuestro repertorio del siglo XVI. Su estilo y relación parecen demostrar que son obra del mismo autor. No tenemos duda de que fue el P. Hernando de Ávila.

51 Vid. en Garzón Blanco, A., «La Tragedia de S. Hermenegildo...», amplia reseña de lo que fue el aparato escénico, págs. 100 y ss. 